\title{
PERCEPTION OF STAKEHOLDERS ON DEVELOPMENT OF REGIONAL BIOECONOMY STRATEGY: THE CASE OF NITRA REGION
}

\author{
Danka MORAVČ́́KOVÁ; Filip TKÁČ \\ Slovak University of Agriculture in Nitra/Faculty of Economics and Management/Department of \\ Social Sciences
}

\begin{abstract}
Purpose: The bio-based economy is a powerfully emerging sector with huge potential and providing employment for many people across the whole Europe. There are still many European regions, including Nitra region in Slovakia, that do not take full advantage of their potential. The H2020 project POWER4BIO aims at supporting these regions in boosting the bio-based economy in their areas and analysing the transition from a realistic and competitive standpoint. Therefore, one of project goals was to ensure the critical mass beyond the consortium by involving additional stakeholders for fostering a dialogue between the consortium members and regional actors.

Design/methodology/approach: This paper introduces the implementation of POWER4BIO methodology for guiding development of regional bioeconomy strategy in Nitra region.

Based on the initial knowledge status of the regional situation and the regional stakeholder map, further methodological steps led to two-stage approach in selection of the group of relevant stakeholders. The workshop and questionnaire survey were realized within the POWER4BIO project in 2019-2020. All stakeholders were contacted firstly personally and then asked for their responses on an electronic survey translated in the Slovak language, and the respondents were provided with detailed explanations and instructions. The sample of stakeholders consisted of representatives of four different categories practitioners/companies, associations of producers, providers and legal entities, policy makers, and academic experts.

Findings: Most of the responding stakeholders declared the appropriate knowledge of the state-of-art dedicated to bioeconomy issues. Responding stakeholders evaluated agriculture as existing, as well as the most promising sector from the point of view of current value chains. The survey has shown on the one hand a lack of private, local and regional financial schemes and funding mechanisms, and on the other hand a lack of knowledge of respondents about available models of public funding at the national and EU level. It has been also evident that the stakeholders mostly rely on public funds and government as a managing authority.

Research limitations: The used approach and methods have limitations due to accuracy of the stakeholder groups and because of prevailing qualitative character of the obtained data and information. Thus, we did not conduct standard statistical quantitative analysis. On the other hand, the strength of this approach and method was that the project team members could ensure stakeholders from different categories were properly engaged in a meaningful way in the process of development of regional bieconomy strategy, and provided with a complex policy and field assessment framework.
\end{abstract}

Key words: bioeconomy development, multi-actor approach, stakeholders' engagement, participatory methods, regional bioeconomy strategy

https://doi.org/10.11118/978-80-7509-820-7-0348 


\section{Introduction}

Bioeconomy has become a crucial issue in development planning and in research and innovation policy making in many parts of the world including the European countries. Bioeconomy strategies and policies are in different developmental stages and the international, national and regional policy making processes have been more or less complex, partly with changing perspectives. Besides international and national initiatives, a number of regional activities have been started and established, followed by the evolving of scientific as well as societal debates on different aspects related to the bioeconomy strategies (Von Braun 2014; Meyer 2017). The European Bioeconomy Strategy and its Action emerged in 2012 from the Innovation Union and Resource Efficient flagship initiatives of the EU 2020 strategy, recognising that the bioeconomy plays a central role in addressing a number of key interlinked challenges (EC 2012). In 2017, a Review of the Bioeconomy was carried out and concluded that the European Bioeconomy Strategy has substantially delivered during the past years on its objectives, leading to the creation of new bio-based value chains, to the development of several national bioeconomy strategies, of dedicated regional platforms and of stakeholder panels, all promoting the development of local bioeconomies valuing local resources and adapted to local needs (EC 2018). One of the key results of the European Bioeconomy Strategy has been to bring the bioeconomy principles and cross-cutting objectives to the attention of national and regional policy-makers. A substantial number of European regions have also included bioeconomy-related priorities in their Research and Innovation Strategies for Smart Specialisation (RIS3). Bioeconomy is an extremely interlinked and diverse world, characterized by strong connections between sectors and with a significant impact on the economy in the European countries (Assobiotec and Intesa Sanpaolo 2020). The pandemic caused by the SARS-COV2 virus has made it more evident that the models of economic development need to be rethought with a greater focus on sustainability and respect for the environment, and the crucial role can be played by public stakeholders, especially in regional and local contexts.

\section{Research Background}

Most of the policy strategy developments in bioeconomy have already adopted a more or less participatory approach by stakeholder conferences, workshops, and surveys. The new European Bioeconomy Strategy explicitly calls for strategic and systematic approaches to bringing all stakeholders together in an attempt at policy coherence (Zeug et al. 2019, p. 5). The development of a bio-based industry is a long-term complex process involving many stakeholders on multiple levels and sectors that could have large impacts on the region. Therefore, the identification of the most appropriate strategy should be based on the involvement of all stakeholders, preferably through a multi-actor approach (Sisto et al. 2016, p. 43; Diaz-Ruiz et al. 2019 , p. 250). Multi-actor approach is a participatory research process in which various actors contribute with their knowledge and experience in different ways (Munda 2008, p. 20; Garmendia and Gamboa 2012, p. 111). This integrated approach 
involves an understanding of technological aspects, economic constraints, social behaviour, the legal and institutional framework, and contextual practices (Campling et al. 2021, p. 2). It can help in decision-making procedures and should empower stakeholders to have an impact on the policy (Dodds and Benson 2010, p. 2). However, this might be quite difficult in regions where a participatory tradition is lacking (including Slovakia), therefore the stakeholders need external expert support that is able to boost their interactive participation in policy-making procedures.

The observed shift to participative dialogue in some strategies is reflected in the establishment of stakeholder forums such as the EU Bioeconomy Panel with members of four stakeholder groups: producers, enterprises and industry; universities, research organisations and the scientific community; public administrations; and civil society. The main objective of these bodies is to support the implementation process of the strategies and to facilitate interactions between different policy areas, sectors, and stakeholders. Their influence on the alignment of overall strategic goals is therefore unclear, and the involvement of end-users still needs to be developed (Meyer 2017, p. 15). Regarding managing innovation in the field of bioeconomy, seven relevant stakeholders' groups are distinguished: policy makers, competitors, universities and research institutes, suppliers, users and customers, consultants, and other actors in the value chain including organizations from previously unrelated industries (Van Lacker et al. 2016, p. 63-64).

Within this framework, the H2020 funded project POWER4BIO was established with the main aim to empower regional stakeholders to boost the transition towards bioeconomy regions in Europe by providing them with the necessary tools, instruments and guidance to develop and implement sound sustainable bioeconomy strategies. The basic principles of multi-actor approach were implemented: (1) focus on the real problems or opportunities that stakeholders are facing; (2) engagement of stakeholders with complementary types of knowledge (scientific, practical and other) which have to join project activities from beginning to end.

\section{Materials and methods}

This paper introduces the implementation of POWER4BIO methodology for guiding development of regional bioeconomy strategy in Nitra region (POWER4BIO 2021). The project methodology contributes to identifying specific regional assets and how-to-develop tips on developing/strengthening its own regional bioeconomy strategy. The main objective of this paper is to explain the individual steps realized in the process of collecting and assessing the perceptions of relevant stakeholders empirically, using the multi-actor approach based on developed project methodological tool, briefly present the two-stage survey results, and to point out the pros and cons of the participatory approach.

The methodology includes both analysis of the regional bioeconomy potential and the development of a stakeholder engagement strategy. Assessing the bioeconomy potential in a region considered the full range of factors to obtain the complete picture. For this aim, a general set of factors where identified seeking to avoid as much as possible subjective parameters and looking for reliable data. 
Additionally, the aspect considered have taken into account the need to be as easy as possible to understand by a large number of stakeholders with different profiles and expertise and provide a useful and comprehensive description of the bioeconomy situation in the region. The set of factors was then grouped in eight categories to make it more accessible for the final user: availability and use of resources, infrastructure and industrial factors, transition towards bioeconomy, public and institutional support/governance/policy framework, funding, research and innovation, market/economic and social and environmental aspects.

Based on the initial knowledge of the regional situation and status, and the regional stakeholder map, further methodological steps led to two-stage approach in selection of the group of relevant stakeholders. The methodology combined a visioning workshop (Stage 1) and four series of questionnaire surveys (Stage 2). The vision generating phase is essential, and participatory workshops with stakeholders could increase the level of acceptance of the results. We carried out intentional sampling procedure related to the project aims and we contacted stakeholders who had showed interest on bioeconomy issues. We classified stakeholders into four basic categories. Table 1 shows the number and structure of stakeholders participating in both stages.

Table 1. Participating stakeholders in individual research stages

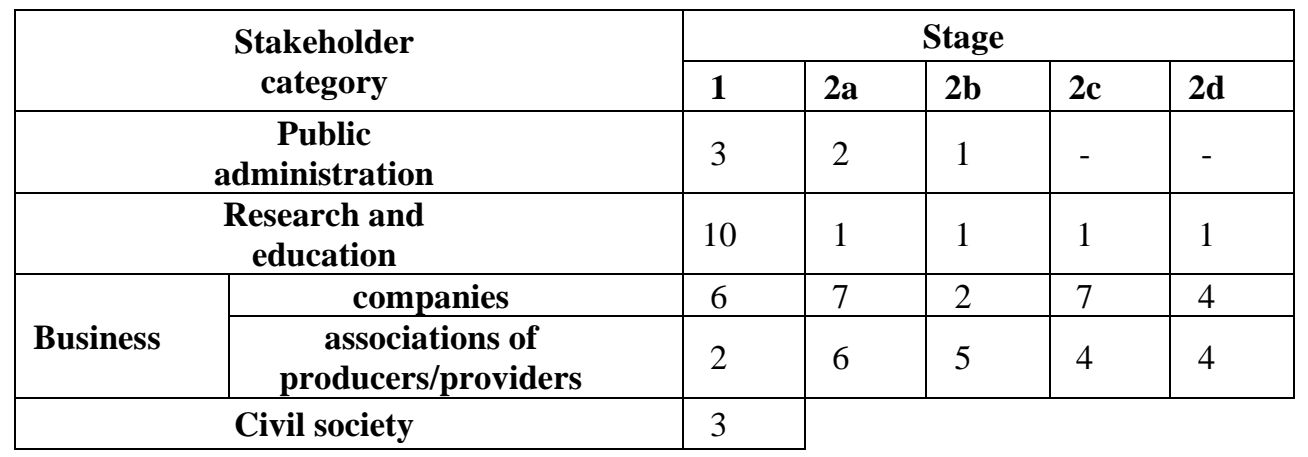

Source: own project survey.

We first contacted and invited stakeholders to participate in the first stage and after that they were asked to continue in the second stage, and also to recommend other relevant stakeholders from their category. Unfortunately, it was very difficult to get decision-makers and representatives of civil society involved. The traditional structure of a dialogue with stakeholders (workshops, questionnaires) does not guarantee the attendance and participation of the same participants in all of them (e.g. Kok et al. 2011). On the other hand, the structure of the participatory approach described in this paper enabled stakeholders to contribute in the whole process from the vision's setting to the definition of strategy's priorities.

The final meeting lasted two days and was organized as an online cross-visit in Nitra region. The group of stakeholders was completed by a number of representatives from the POWER4BIO project consortium and by external registered 
participants from different stakeholder categories. Table 2 provides an overview of basic data about all mentioned events and activities.

Table 2. Overview of basic data about project events and activities

\begin{tabular}{|c|c|c|c|}
\hline Event/activity & $\begin{array}{c}\text { Length } \\
\text { (days) }\end{array}$ & $\begin{array}{c}\text { Number of } \\
\text { participants* }\end{array}$ & Main results \\
\hline $\begin{array}{c}\text { Visioning } \\
\text { workshop }\end{array}$ & 1 & $30(6 / 24)$ & $\begin{array}{c}\text { Consensus on main regional } \\
\text { bioeconomy drivers and focus areas, } \\
\text { identification of barriers and } \\
\text { challenges }\end{array}$ \\
\hline $\begin{array}{c}\text { Questionnaire } \\
\text { surveys }\end{array}$ & 30 & 46 & $\begin{array}{c}\text { Reflection of opinion of stakeholders } \\
\text { well acquainted with the regional } \\
\text { situation }(8 \text { topic areas) }\end{array}$ \\
\hline Cross-visit & 2 & $58(33 / 25)$ & $\begin{array}{c}\text { Improved identification of strategic } \\
\text { priorities, proposals of concrete } \\
\text { actions and mechanisms }\end{array}$ \\
\hline
\end{tabular}

*Including participating members of the project consortium.

Source: own project survey.

The main objective of cross-visit was to motivate participants to contribute to presented information and ideas, and to share their experiences in order to improve the concept of the regional bioeconomy model. The used methodology included a mix of tools, e.g. moderated discussion, chat (during the meeting), mail communication (after the meeting), and mind mapping method using software tool (during and after the meeting).

\section{Results and discussion}

Visioning workshop participants agreed that a non-existent state or regional bioeconomy strategy is a key burden for the transition to this economy model. Subsequently, the main features of the bioeconomy and its potential in the Nitra region as well as in Slovakia were defined through various brainstorming methods. Separation and use of municipal waste, unused food and food production residues, as well as an interdisciplinary approach to tackling value chains, industrial symbiosis, changes in consumer thinking and behaviour, responsible water management, legislative optimization, the development of bioplastics, degradable and compostable packaging as well as social aspects such as creating conditions for the development of social agriculture were considered as the main potential bioeconomy drivers. The areas of agriculture, forestry, food and renewable energy were considered as focus areas for bioeconomy development in the Nitra region. Key problems identified by the respondents were funding, demand for organic products, the biomass market, the availability of conversion technologies, valorisation of byproducts, and waste management. This workshop was also used to discuss and identify regional barriers and challenges for bioeconomy development.

The purpose of the second stage of the survey was to add critical mass beyond the project consortium by bringing additional stakeholders, particularly practitioners, 
into continuous contact with project activities. In addition to map the regional bioeconomy status, the aim was to include market players who are well acquainted with the regional bioeconomy situation into the survey which covered eight topic areas (mentioned in chapter Materials and methods). The majority $(56 \%)$ of the respondents believed that there was no officially approved bioeconomy strategy in their region. Regarding the most crucial sector of focus in the development of a bioeconomy strategy, 11 out of 16 respondents identified agriculture as the area of leading importance, followed by forestry, the food industry, the renewable energy sector, nature tourism, and recreation.

When asked to identify a candidate for an entity that could oversee the development of a bioeconomy strategy, respondents favoured a multisector approach, with the most prominent proposal calling for the development of the strategy by a team of experts assembled jointly by the respective ministries of the economy, agriculture, and environment. Respondents recommended that the strategy should be developed in close consultation with regional and municipal governments, as well as the professional, academic, and scientific communities. Most respondents selected 'financial problems' and 'lack of sufficient demand for advanced bio-based products' as most prominently hindering the use of agricultural residues in bio-based value chains, while the three most important actors in the value chain relating to agricultural residues were identified as farmers, universities, and industrial facilities. Respondents gave similar answers in the case of conventional arable crops and energy crops, with biomass trade and logistics/transportation additionally identified as problems in the case of energy crops. There was other significant consensus in the case of industrial wastes and by-products (most respondents identified the availability of conversion technology) and wastes of livestock (respondents identified 'financial problems' and 'logistical and transportation problems'). Respondents identified biofuels and food products as the most important currently available products generated from bioresources in their region. Additionally, almost all respondents believed that high costs and a high risk of failure were the primary challenges to greater market introduction.

Respondents gave a wide variety of answers when asked to identify the most significant value chain in their region but identified agriculture as the most significant sector both currently and in its potential for future expansion, and food products and biofuels as the most widely preferred products. 10 of the 16 respondents identified 'deepening mutual communication and knowledge transfer' as the most important area of development for increasing the potential for collaboration between different regions, and 8 out of the respondents selected 'creating joint research and development actions together with a combination of private and public financing models' as the second most important. With regard to the financing of bioeconomy projects, 7 respondents identified the agriculture sector as already receiving external funding, with the national government as the most important source of external funding. Respondents identified 'structural funds and their implementation programs,' 'H2020 through debts and equity financing via the EIB's InnovFin financial programme,' and 'H2020 through grants' as the most important funding sources. Concerning the benefits and drawbacks of public and private funding, 
respondents identified shorter approval time as the primary benefit, and 'difficulties related to ending up the private investment,' 'not efficient amount of money to cover indirect costs,' and 'complicated prediction of funded areas' as the bottlenecks of private funding. The primary benefit of public funding was identified as its helpfulness during financial gaps, while its main drawback ( 7 respondents), was the duration of the administration process associated with these funds.

\section{Conclusions and recommendations}

The paper shows that the multi-actor approach could be an effective tool to manage in a participatory way the development of regional bioeconomy strategy. However, the process (and its results) has a number of both advantages and disadvantages. The first advantage of this approach is that the project team members could ensure stakeholders from different categories were properly engaged in a meaningful way in the process of development of regional bieconomy strategy, and they were provided with a complex policy and field assessment framework. Secondly, it builds trust and relations between different stakeholder groups, as well as it generates positive outcomes, like new partnerships, contacts, and extended knowledge about funding opportunities etc. Moreover, using participatory methods helps stakeholder groups to identify their priorities, their positions on key issues, and to think about future perspectives from their point of view. It also helps decisionmakers better to understand what stakeholders want and why.

On the other hand, the used approach has limitations due to accuracy of the stakeholder groups and because of prevailing qualitative character of the obtained data and information. Future steps should include higher number of participating stakeholders and the combination of more quantitative and qualitative methods of data collection. Furthermore, the division of stakeholders into a core group of important ones and a group containing less crucial actors, as well as multiregional insights accompanied with case studies offering microlevel perspectives would significantly contribute to the development of targeted regional bioeconomy strategy and policy. In order to transform identified strategic priorities in concrete action plans, the identified barriers should be analysed more in detail with the objective clearly to define support actions and mechanisms, with management responsibilities and the time reference period. Finally, it can be concluded from the demonstrated experience in the POWER4BIO project that although this approach is logistically complicated and methodologically challenging, combination of various participative methods can support the process of creating consistent scenario of bioeconomy development in the regional context. Indication of some disadvantages can help to avoid potential pitfalls in the future implementation of multi-actor approach.

\section{References}

1. Assobiotec and Intesa Sanpaolo (2020), Bioeconomy in Europe $6^{\circ}$ Report, https://assobiotec.federchimica.it/docs/default-source/default-documentlibrary/bioeconomia-executive-summary.pdf?sfvrsn=4233127c_0 (access: 05-April-2021). 
2. Campling, P., Joris, I., Calliera, M., Capri, E., Marchis, A., Kuczyńska, A., Vereijken, T., Majewska, Z., Belmans, E., Borremans, L., Dupon, E., Pauwelyn, E., Mellander, P. E., Fennell, Ch., Fenton, O., Burgess, E., Puscas, A., Gil, E. I., Lopez de Alda, M., Tudel, G. F., Andersen, E., Højber, A. L., Nowakowska, M., Suciu, N. (2021), A multi-actor, participatory approach to identify policy and technical barriers to better farming practices that protect our drinking water sources, „Science of The Total Environment”, 2, 755, 142971. https://doi.org/10.1016/j.scitotenv.2020.142971

3. Diaz-Ruiz, R., Costa-Font, M., López-i-Gelats, F., Gil, J. M. (2019), Food waste prevention along the food supply chain: A multi-actor approach to identify effective solutions, „Resources, Conservation and Recycling”, 149, pp. 249-260. https://doi.org/10.1016/j.resconrec.2019.05.031

4. Dodds, F. and Benson, E. (2010), Multistakeholder Dialogues Toolkit, CIVICUS, Johannesburg.

5. European Commission. (2012), Innovating for Sustainable Growth. A Bioeconomy for Europe, https://ec.europa.eu/information_society/newsroom/image/document/20186/review_of_2012_eu_bes_2E89B85F-950B-9C84-5B426D1C24851387_49692.pdf (access: 05-April-2021).

6. European Commission (2018), Review of the 2012 European Bioeconomy Strategy, https://ec.europa.eu/information_society/newsroom/image/document/20186/review_of_2012_eu_bes_2E89B85F-950B-9C84-5B426D1C24851387_49692.pdf (access: 05-April-2021).

7. Garmendia, E. and Gamboa, G. (2012), Weighting social preferences in participatory multicriteria evaluations: A case study on sustainable natural resource management, „Ecological Economics", 84, pp. 110-120. https://doi.org/10.1016/j.ecolecon.2012.09.004

8. Kok, K., van Vliet, M., Bärlund, I., Dubel, A. and Sendzimir, J. (2011), Combining participative backcasting and exploratory scenario development: Experiences from the SCENES project, „Technological Forecasting \& Social Change“, 78, 5, pp. 835-851. https://doi.org/10.1016/j.techfore.2011.01.004

9. Meyer, R. (2017), Bioeconomy Strategies: Contexts, Visions, Guiding Implementation Principles and Resulting Debates, „Sustainability”, 6, 9, 1031. https://doi.org/10.3390/su9061031

10. Munda, G. (2008), Social Multi-Criteria Evaluation for a Sustainable Economy, Springer, Berlin.

11. POWER4BIO (2021), POWER4BIO BSAT (Deliverable 2.5), http://bioeconomy-strategytoolkit.eu/ (access: 05-April-2021).

12. Sisto, R., Vliet, M., Prosperi, M. (2016), Puzzling stakeholder views for long-term planning in the bio-economy: A back-casting application, „Futures”, 76, pp. 42-54. https://doi.org/10.1016/j.futures.2015.04.002

13. Van Lancker, J., Wauters, E., Van Huylenbroeck, G. (2016), Managing innovation in the bioeconomy: An open innovation perspective, „Biomass and Bioenergy”, 90, pp. 60-69, https://doi.org/10.1016/j.biombioe.2016.03.017

14. Von Braun, J. (2014), Bioeconomy and sustainable development-Dimensions, „Rural”, 21, pp. 6-9.

15. Zeug, W., Bezama, A., Moesenfechtel, U., Jähkel, A., Thrän, D. (2019), Stakeholders' Interests and Perceptions of Bioeconomy Monitoring Using a Sustainable Development Goal Framework, ,Sustainability”, 6, 11, 1511. https://doi.org/10.3390/su11061511 